\title{
AVALIAÇÃO DO PROGRAMA DE ALIMENTAÇĀO DO TRABALHADOR, NO ESTADO DE PERNAMBUCO, BRASIL
}

Josenilda Barreto de Moura*

MOURA, J.B. de Avaliação do programa de alimentação do trabalhador, no Estado de Pernambuco, Brasil, Rev. Saúde públ., S. Paulo, 20:115-28, 1986.

RESUMO: Foi avaliado o Programa de Alimentação do Trabalhador (PAT), no que se refere a implantação, funcionamento e resultados em empresas, no Estado de Pernambuco, Brasil. O universo pesquisado abrangeu um total de 130 empresas, sendo 85 inscritas no PAT entre 1977 e 1980 e 45 não inscritas. Neste grupo, a coleta de dados limitou-se ao ano de 1980 e teve como finalidade o estabelecimento de parâmetros para avaliar os indicadores de impacto do Programa. A análise dos cardápios sugere que um reduzido percentual de empresas fornece refeições conforme as exigências mínimas de energia e proteína estabelecidas pela Lei $6.321 / 76$, isto é, um mínimo de $1.400 \mathrm{cal}$ e $\mathrm{NDpCal} \%$ superior a 6 . O exame dos indicadores de impacto nas empresas dos dois grupos sugere que o PAT não modificou o número de acidentes de trabalho, condições de saúde e rotatividade dos trabalhadores; tendo apenas influído no absenteísmo.

UNITERMOS: Programas de nutrição. Estudos de avaliação. Trabalhadores

\section{INTRODUÇÃO}

Estudos desenvolvidos em várias partes do mundo $2, \mathbf{3}, \mathbf{4}, \mathbf{1 2 , 1 3}$ têm comprovado a inter-relação da ingestão calórica e produtividade, evidenciando as implicações de um suprimento alimentar inadequado às necessidades vitais sobre o rendimento do trabalho. A produtividade aumenta até o ponto em que a dieta é considerada adequada (para a superfície corporal, idade, sexo, clima, atividade e estado de saúde), não existindo evidências de que a adição de nutrientes melhore a saúde ou a eficiência de quem já está adequadamente alimentado.

Isto evidencia a importância da alimentação no equilíbrio orgânico, não apenas como fator para a manutençāo da saúde mas, do ponto de vista econômico, como condição para maior dispêndio de energia e, consequientemente, maior capacidade de trabalho.

No Brasil, o modelo econômico adotado em busca do crescimento e desen. volvimento resultou numa crescente defasagem entre salário real e poder de compra ${ }^{11}$. Essa diminuição do poder aquisitivo tem ressonâncias negativas no estado de nutrição do indivíduo e, consequientemente, no desenvolvimento nacional.

Face a grande parcela da população economicamente ativa do país não alcançar o nível de renda mínimo, o Governo Brasileiro tem procurado suplementar esta renda através de programas de ação, como forma indireta de distribuição de renda e incremento ao crescimento e desenvolvimento econômico ${ }^{1}$.

Consoante esta diretriz política foi criado, em 1972, o Instituto Nacional de Alimentação e Nutrição (INAN), cujo objetivo básico consiste em "promover e organizar atividades de assistência alimentar e nutricional, a cargo do Governo, prioritariamente dirigidas ao atendimento de grupos vulneráveis da popula-

\footnotetext{
*Da Delegacia Regional de Trabalho em Pernambuco. Av. Guararapes, 253/506 - 50.000 - Recife, PE. - Brasil.
} 
MOURA, J.B. de Avaliação do programa de alimentação do trabalhador, no Estado de Pernambuco, Brasil. Rev. Saúde públ., S. Paulo, 20: 115-28, 1986.

ção brasileira, no campo de abrangência das finalidades sociais que inspiraram a sua instituição". Em 30 de março de 1973, foi aprovado o I Programa Nacional de Alimentação e Nutrição (I PRONAN); em 1976, suge o II PRONAN, o qual estabeleceu a política alimentar e nutricional do país para o período de 1976 a $1979^{6}$.

Integrando a programação básica do PRONAN, destaca-se o Programa de Alimentação do Trabalhador (PAT), institucionalizado pela Lei 6.321 , de 14 de abril de $1976^{10}$, e que tem por objetivo ${ }^{6}$ proporcionar facilidades para a alimentação de trabalhadores de baixa renda, visando:

- melhorar as condições de saúde do trabalhador;

- aumentar a produtividade no trabalho;

- reduzir os índices de absenteísmo e de acidentes de trabalho.

O PAT preconiza que as despesas com a alimentação sejam divididas entre 0 trabalhador $(20 \%)$, o Governo Federal $(48 \%)$ e a empresa (32\%), cabendo ainda a esta última o investimento nos serviços ${ }^{10}$.

Decorridos quase dez anos da criação do PAT, pareceu oportuna a realização de estudo para verificar seu funcionamento e resultados obtidos nas empresas beneficiadas no Estado de Pernambuco, Brasil.

O levantamento de informações sobre a atuação do Programa possibilitou, através dos critérios e indicadores propostos, avaliar a situação à época, verificando até que ponto o PAT definiu adequadamente seus objetivos, os progressos alcançados e prováveis áreas de estrangulamento. Possibilitou, também, sugerir às autoridades competentes as modificações necessárias à reformulação do Programa, visando aumentar a receptividade por parte das empresas.

\section{MATERIAL E METODOS}

Dois conjuntos de empresas constituíram o universo em estudo, para fins de análise denominadas grupo experimental (empresas inscritas no PAT) e grupo controle (empresas não inscritas no PAT).

O grupo experimental foi composto pelo universo das empresas inscritas entre 1977 e 1980 , em Pernambuco, totalizando 85 unidades com $4,3,2$ e 1 ano de participação no Programa.

A coleta dos dados, no grupo experimental, foi realizada a partir do ano anterior ao da implantação do Programa (considerado ano 0) na empresa; enquanto no grupo controle limitou-se ao ano de 1980 , desde que tais informações servissem apenas de parâmetro para avaliar os indicadores de impacto do PAT, ao término do período pesquisado, 1976 a 1980.

\section{Critérios para Classificar as Empresas}

\section{Atividade econômica}

GRUPO A: Indústrias tecnologicamente mais sofisticadas

GRUPO B: Indústrias mais intensivas em mão-de-obra: Empresas que utilizam tecnologias menos sofisticadas, exigindo, conseqüentemente, maior esforço muscular

GRUPO C: Atividades de comércio e prestação de serviços

\section{Tamanho}

O número de empregados foi considerado a variável-chave para a mensuração do tamanho da empresa. A opção por este critério baseou-se em sua aparente consistência, quando relacionadas com dados de ordem econômica ${ }^{7}$. Assim sendo, foi definida como pequena a empresa com até 99 empregados; média, de 100 a 499 servidores, e grande, aquela cujo efetivo ultrapassava 499 trabalhadores.

O grupo controle foi formado por 45 empresas considerando-se, para sua com- 
MOURA, J.B. de Avaliação do programa de alimentação do trabalhador, no Estado de Pernambuco, Brasil. Rev. Saúde públ., S. Pauḷ, 20: 115-28, 1986.

posição, os critérios anteriormente citados. A previsão para esta amostra foi de 15 empresas de cada ramo de atividade (A, B e C), distribuídas em 5 empresas pequenas, 5 médias e 5 grandes. Portanto, o universo pesquisado atingiu um total de 130 empresas (72 situadas no Município do Recife, 46 na Região Metropolitana e 12 no interior do Estado de Pernambuco).

\section{Produtividade}

Admite-se que o aumento da produtividade, mencionada entre os objetivos do PAT, refere-se ao aumento da produtividade média da mão-de-obra, a qual é decorrente da ação de vários fatores, e para ser medida exige que todos os fatores que a influenciam se mantenham constantes. Entretanto, esses fatores dificilmente podem ser controlados, daí resultando a dificuldade de mensuração. Neste caso, só seria possível quantificar a produtividade média da mão-de-obra mediante o emprego de fórmulas econométricas bastante sofisticadas, as quais não foram aqui utilizadas por fugirem ao escopo do trabalho.

Diante disto, procurou-se avaliar o comportamento da produtividade média da mão-de-obra através de alguns indicadores indiretos, como sejam: licenças médicas, acidentes de trabalho, absenteísmo, rotatividade e conteúdo energético/ protéico das refeições.

Quantificou-se os trabalhadores por faixa de salário-mínimo, visando determinar o percentual de baixa renda beneficiado pelo PAT.

Os serviços de alimentação foram divididos em próprio e de terceiros, este último com as modalidades comodato, refeição pronta e refeição convênio.

Com relação ao conteúdo energético/ protéico, determinou-se o consumo "per capita" de calorias e respectivo NDpCal\% do almoço servido nas empresas do grupo experimental; visto que a Lei 6.321/
76 estabelece um aporte mínimo de 1.400 calorias e $\mathrm{NDpCal} \%$ superior a $6^{11}$.

$\mathrm{O}$ conteúdo de calorias e proteína bruta foi obtido através da 'Tabla de composición de alimentos para uso en America Latina"s, enquanto a proteína líquida foi determinada conforme orientação do PAT, ou seja, utilizando-se os fatores de correção: cereais - 0,5 ; leguminosas - 0,6; e produtos de origem animal 0,7 .

O tratamento estatístico dos dados foi realizado mediante o teste ANOVA, e dois outros testes, baseados respectivamente nas distribuições $F$ e $t$-Student ${ }^{9}$. Cabe salientar que a zona de rejeição foi de $5 \%$, tanto para os testes unicaudais quanto para os bicaudais.

\section{RESULTADOS E COMENTÁRIOS}

Distribuiçâo das Empresas não Inscritas no PAT, Conforme Atividade Econômica e Tamanho

Nas empresas do grupo controle a distribuição por atividade econômica $\mathrm{A}, \mathrm{B}$ e $C$ foi de $31,11,35,56$ e $33,33 \%$, respectivamente (Tabela 1), bem próxima à distribuição do grupo experimental.

\section{TABELA I}

Distribuição amostral das empresas não inscritas no Programa de Alimentação do Trabalhador, conforme atividade econômica e tamanho - Pernambuco, 1980

\begin{tabular}{lrr}
\hline Especificação & $n .^{\circ}$ & $\%$ \\
\hline Atividade econômica & & \\
A & 14 & 31,11 \\
B & 16 & 35,56 \\
C & 15 & 33,33 \\
Total & 45 & 100,00 \\
Tamanho & & \\
$\quad$ Pequena & 16 & 35,56 \\
$\quad$ Média & 19 & 42,22 \\
$\quad$ Grande & 10 & 22,22 \\
Total & 45 & 100,00 \\
& & \\
\hline
\end{tabular}


MOURA, J.B. de Avaliação do programa de alimentação do trabalhador, no Estado de Pernambuco, Brasil. Rev. Saúde públ., S. Paulo, 20: 115-28, 1986.

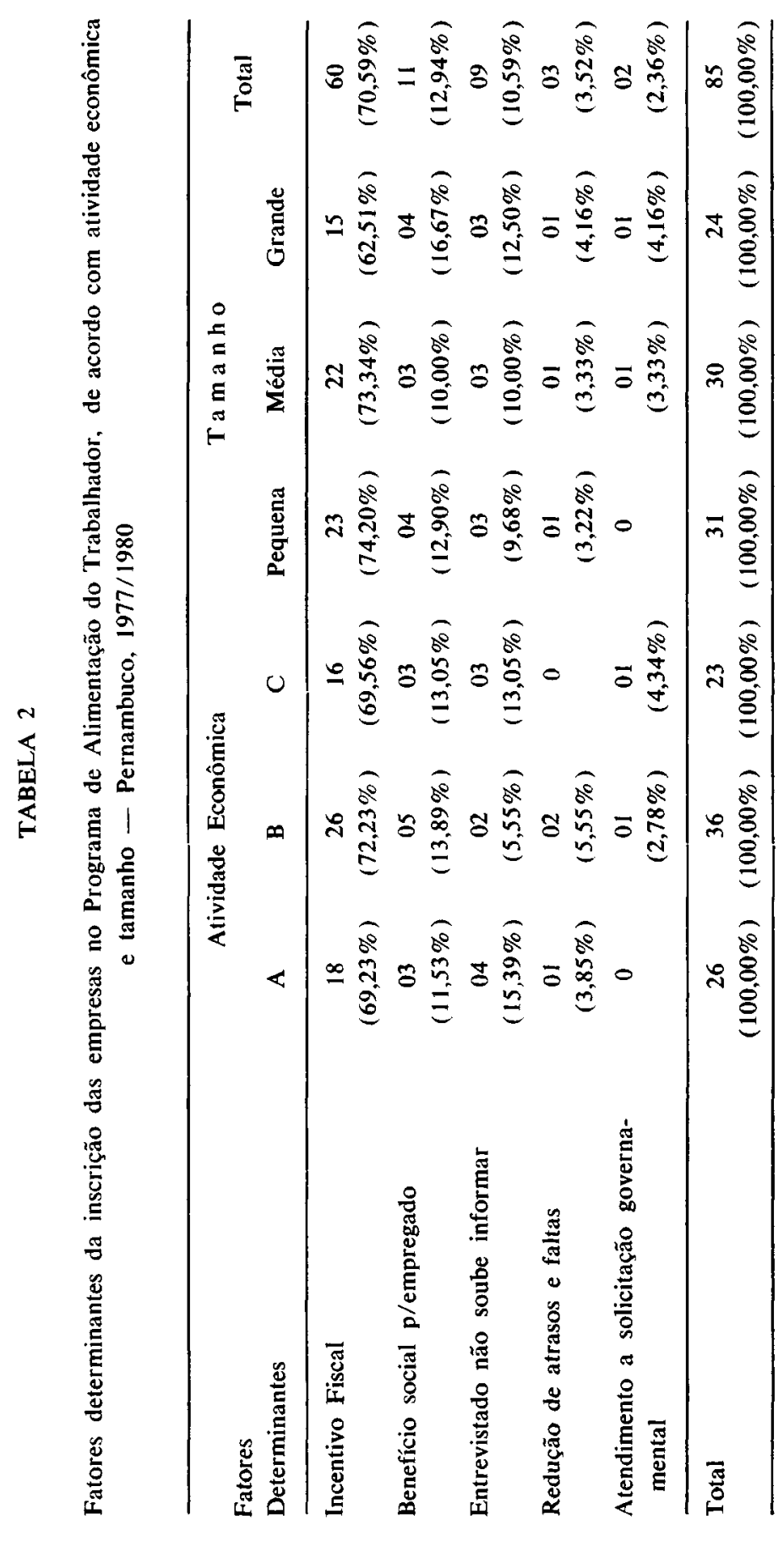


MOURA, J.B. de Avaliação do programa de alimentação do trabalhador, no Estado de Pernambuco, Brasil. Rev. Saúde públ., S. Paulo, 20: 115-28, 1986.

Considerando-se o tamanho das empresas deste estrato amostral, $35,56 \%$ eram pequenas, $42,22 \%$ médias $e$ 22,22\% grandes (Tabela 1). Esta distribuição afastou-se um pouco dos critérios previamente estabelecidos de amostragem proporcional, em razão da dificuldade em se obter empresas, principalmente de grande porte, nos três ramos de atividade econômica pesquisados.

Determinantes da Inscrição e não Inscrição das Empresas no PAT, Segundo Atividade Econômica e Tamanho

As empresas beneficiadas pelo PAT, em Pernambuco, ingressaram no Programa motivadas, em primeiro lugar, pelo incentivo fiscal $(70,59 \%)$. Em segundo plano, encontra-se o benefício social proporcionado ao empregado $(12,94 \%)$, seguido da redução de atrasos e faltas $(3,52 \%)$ e atendimento a solicitação governamental $(2,36 \%)$. Excluindo-se o segundo fator determinante da inscrição das empresas, constata-se que $76,47 \%$ estão ligados a benefícios para a própria empresa (Tabela 2).

Vale ressaltar que, dentre as 85 empresas inscritas, $61(71,77 \%)$ já ofereciam alimentação aos empregados antes da inscrição no PAT, mostrando que os incentivos fiscais não favoreceram a criação de serviços de alimentação para trabalhadores.

Entre os motivos da não participação de empresas no Programa foram apontados, em ordem decrescente: indecisão da Diretoria (28,89\%); desconhecimento da Lei $6.321 / 76(17,78 \%)$, principalmente entre as pequenas empresas; incentivo fiscal e lucro não condizentes com o investimento financeiro $(13,33 \%)$; e residência dos empregados próxima à empresa $(4,44 \%)$. E importante constatar que a maioria dos entrevistados não soube informar os motivos da não participação de suas empresas no Programa $(35,56 \%)$.

Merece realce o desconhecimento dos incentivos fiscais à alimentação do trabalhador, nas empresas de pequeno porte $(37,50 \%)$ e de atividade econômica C (20,00\%), sugerindo a necessidade de maior divulgação do PAT entre as mesmas (Tabela 3).

\section{Indicadores de Impacto do PAT}

- Licenças médicas, acidentes de trabalho, absenteísmo e rotatividade, nas empresas inscritas no PAT conforme o ano cronológico.

A análise dos dias de licenças médicas sugere que não houve elevação da incidência ou prevalência de alguma doença entre 1976 e 1980. Por outro lado, a instabilidade do número de acidentes em relação aos anos de estudo não permite afirmativas incisivas sobre o assunto. Com relação aos dias perdidos por acidentes de trabalho e rotatividade, observou-se um declínio, embora inconstante, enquanto o absenteísmo apresentou uma redução ano após ano, ao longo do período pesquisado (Tabela 4). 


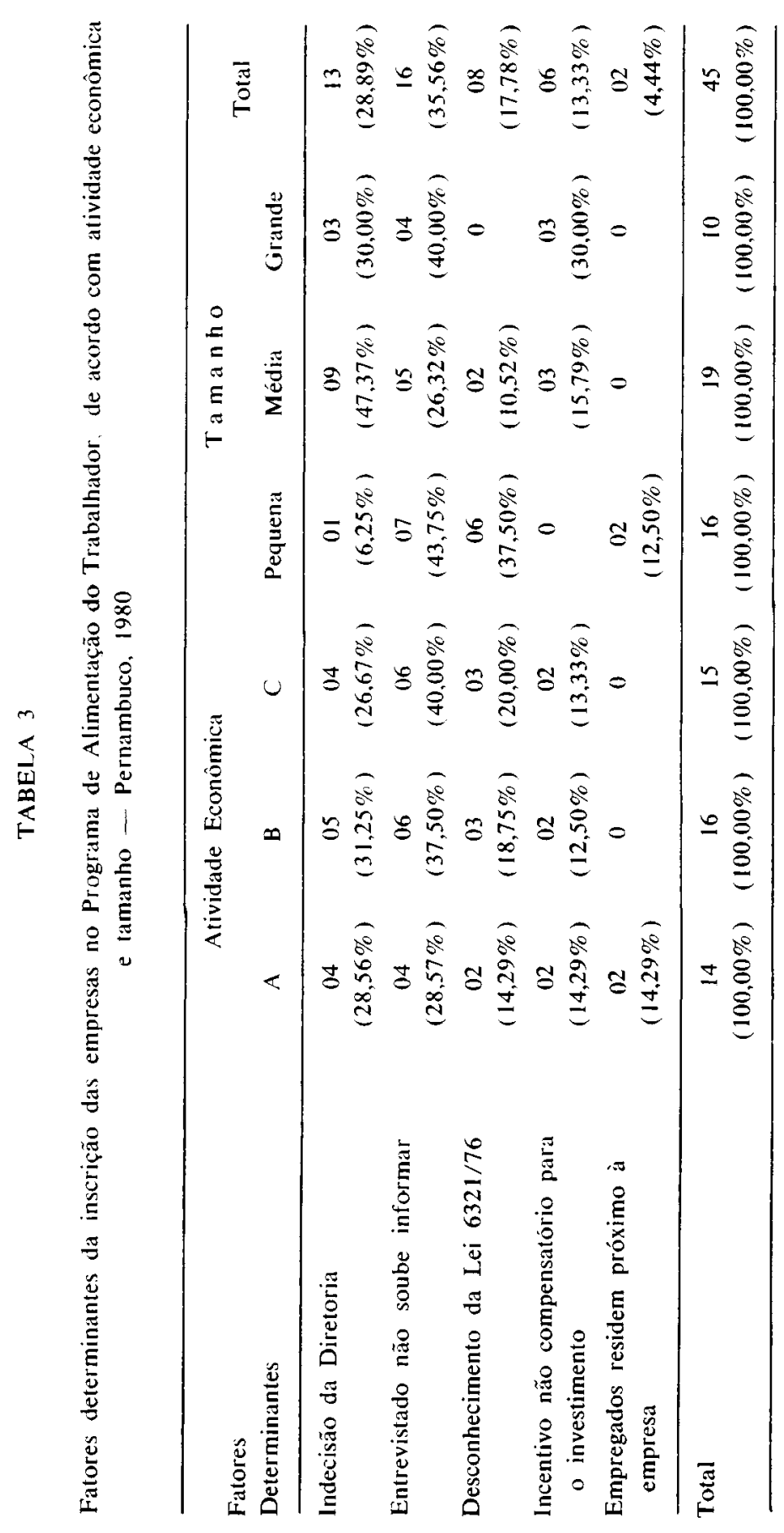


MOURA, J.B. de Avaliação do programa de alimentação do trabalhador, no Estado de Pernambuco, Brasil. Rev. Saúde públ., S. Paulo, 20: 115-28, 1986.

\section{TABELA 4}

Licenças médicas, acidentes de trabalho, absenteísmo e rotatividade por trabalhador, segundo ano cronológico - Pernambuco, 1976/1980

\begin{tabular}{lccccc}
\hline Ano & $\begin{array}{c}\text { Licença } \\
\text { Médica } \\
\text { (dias) }\end{array}$ & $\begin{array}{c}\text { Acidentes de Trabalho } \\
\text { N. }^{\circ}\end{array}$ & $\begin{array}{c}\text { dias } \\
\text { Absenté́smo } \\
\text { (dias) }\end{array}$ & $\begin{array}{c}\text { Rotati- } \\
\text { vidade } \\
(\%)\end{array}$ \\
\hline 1976 & 4,61 & 0,08 & 1,83 & 3,04 & 49,90 \\
1977 & 3,89 & 0,07 & 1,40 & 2,61 & 51,91 \\
1978 & 4,27 & 0,11 & 1,47 & 2,26 & 64,74 \\
1980 & 3,72 & 0,05 & 0,88 & 1,95 & 46,52 \\
\hline
\end{tabular}

TABELA 5

Dias de licença médica, acidentes de trabalho, absenteísmo e rotatividade por trabalhador/ano nas empresas inscritas no Programa de Alimentação do Trabalhador, conforme anos de incentivo - Pernambuco, 1976/1980.

\begin{tabular}{|c|c|c|c|c|c|c|}
\hline $\begin{array}{l}\text { Anos de } \\
\text { Incentivo }\end{array}$ & $\begin{array}{l}\text { Licença } \\
\text { médica }\end{array}$ & $\mathrm{N} .^{\circ}$ & $\begin{array}{c}\text { identes de } T \\
\text { dias } / \\
\text { trabalhador }\end{array}$ & $\begin{array}{l}10 \\
\text { dias/ } \\
\text { acidente }\end{array}$ & $\begin{array}{l}\text { Absen- } \\
\text { teísmo }\end{array}$ & $\begin{array}{c}\text { Rotati- } \\
\text { vidade }(\%)\end{array}$ \\
\hline \multicolumn{7}{|l|}{1 ano } \\
\hline ano 0 & 4,22 & 0,02 & 0,72 & 23,69 & 2,01 & 45,07 \\
\hline ano 1 & 4,42 & 0,03 & 1,17 & 21,21 & 1,46 & 49,09 \\
\hline \multicolumn{7}{|l|}{2 anos } \\
\hline ano 0 & 5.67 & 0,18 & 1,82 & 13,20 & 2,37 & 82,96 \\
\hline ano 1 & 4,05 & 0.07 & 1,05 & 36,15 & 1,90 & 53,37 \\
\hline ano 2 & 3.97 & 0,07 & 1,31 & 24,98 & 1,53 & 46,79 \\
\hline \multicolumn{7}{|l|}{3 anos } \\
\hline ano 0 & 4,13 & 0,06 & 1,32 & 15,39 & 1,73 & 53,77 \\
\hline ano 1 & 3,59 & 0,07 & 0,88 & 16,84 & 1,37 & 54,94 \\
\hline ano 2 & 3,29 & 0,04 & 0,74 & 17,28 & 1,26 & 42,96 \\
\hline ano 3 & 3,67 & 0,04 & 0,60 & 18,98 & 1,32 & 41,71 \\
\hline \multicolumn{7}{|l|}{4 anos } \\
\hline ano 0 & 4,61 & 0,09 & 1,64 & 23,87 & 3,14 & 48,00 \\
\hline ano 1 & 3,78 & 0,08 & 1,22 & 26,21 & 3,94 & 51,54 \\
\hline ano 2 & 3,52 & 0,07 & 1,06 & 22,28 & 3,47 & 50,09 \\
\hline ano 3 & $2,8 \mathrm{I}$ & 0,05 & 0,79 & 23,75 & 3,16 & 45,14 \\
\hline ano 4 & 2.94 & 0,04 & 0,71 & 33,83 & 2,29 & 39,52 \\
\hline
\end{tabular}


MOURA, J.B. de Avaliação do programa de alimentação do trabalhador, no Estado de Pernambuco, Brasil. Rev. Saúde públ., S. Paulo, 20: 115-28, 1986.

Licenças Médicas, Acidentes de Trabalho, Absenteísmo e Rotatividade nas Empresas Inscritas no PAT, por Anos de Incentivo

A média de dias de licença variou entre 2,81 e 5,67 por trabalhador/ ano ( $\mathrm{Ta}$ bela 5), o que parece refletir a precária situação de saúde do trabalhador, com evidente prejuízo econômico para o Estado, pela consequiente redução na produtividade; acresce a isto, o dado imensurável constituído pela redução da resistência física do homem.

Os achados sobre os acidentes de trabalho sugerem, aparentemente, que o PAT provocou impacto sobre o número de eventos e dias perdidos por trabalhador, o que não acontece com os dias perdidos por acidente. Convém observar que o Programa não se propôs reduzir este último indicador (gravidade do acidente), para o que seriam necessárias medidas de minimização de riscos.

Por outro lado, os anos de incentivo parecem ter influído no absenteísmo, vez que estas taxas sofreram redução ao longo do período.
Registrou-se um decréscimo na rotatividade por ano de incentivo, exceção feita àquelas empresas com apenas um ano de benefício. E possível que a Lei $6.708 / 79$, que normatizou a correção semestral dos salários, tenha provocado maior impacto na rotatividade das empresas com apenas um ano de benefício, já que $50 \%$ das mesmas eram de pequeno porte (economicamente mais frágeis).

\section{Salário dos Trabalhadores Conforme o Tamanho das Empresas}

Enfocando a situação salarial conforme o tamanho das empresas, observa-se maior concentração de trabalhadores com renda até dois salários-mínimos, nas empresas incentivadas de pequeno $(60,51 \%)$ e médio porte $(62,60 \%)$; enquanto, nas grandes empresas, apenas $37,73 \%$ dos trabalhadores estão nesta faixa salarial (Tabela 6). O grupo das não incentivadas mostra a mesma tendência, isto é, maior percentual de empregados das pequenas $(59,16)$ e médias $(65,33)$ empresas percebendo até dois salários-mínimos; nas de grande porte, apenas $42,78 \%$ estão nesta faixa salarial.

TABELA 6

Distribuição percentual dos trabalhadores nos grupos estudados, por faixa de salário-mínimo e tamanho das empresas - Pernambuco, 1980

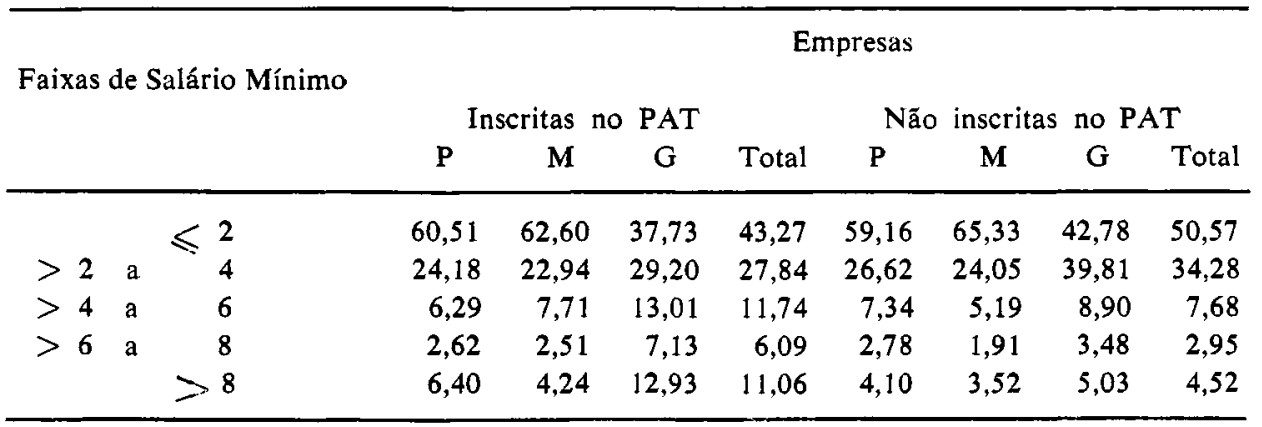

$$
\begin{aligned}
& \mathrm{P}=\text { Pequena } \\
& \mathbf{M}=\text { Média } \\
& \mathrm{G}=\text { Grande }
\end{aligned}
$$




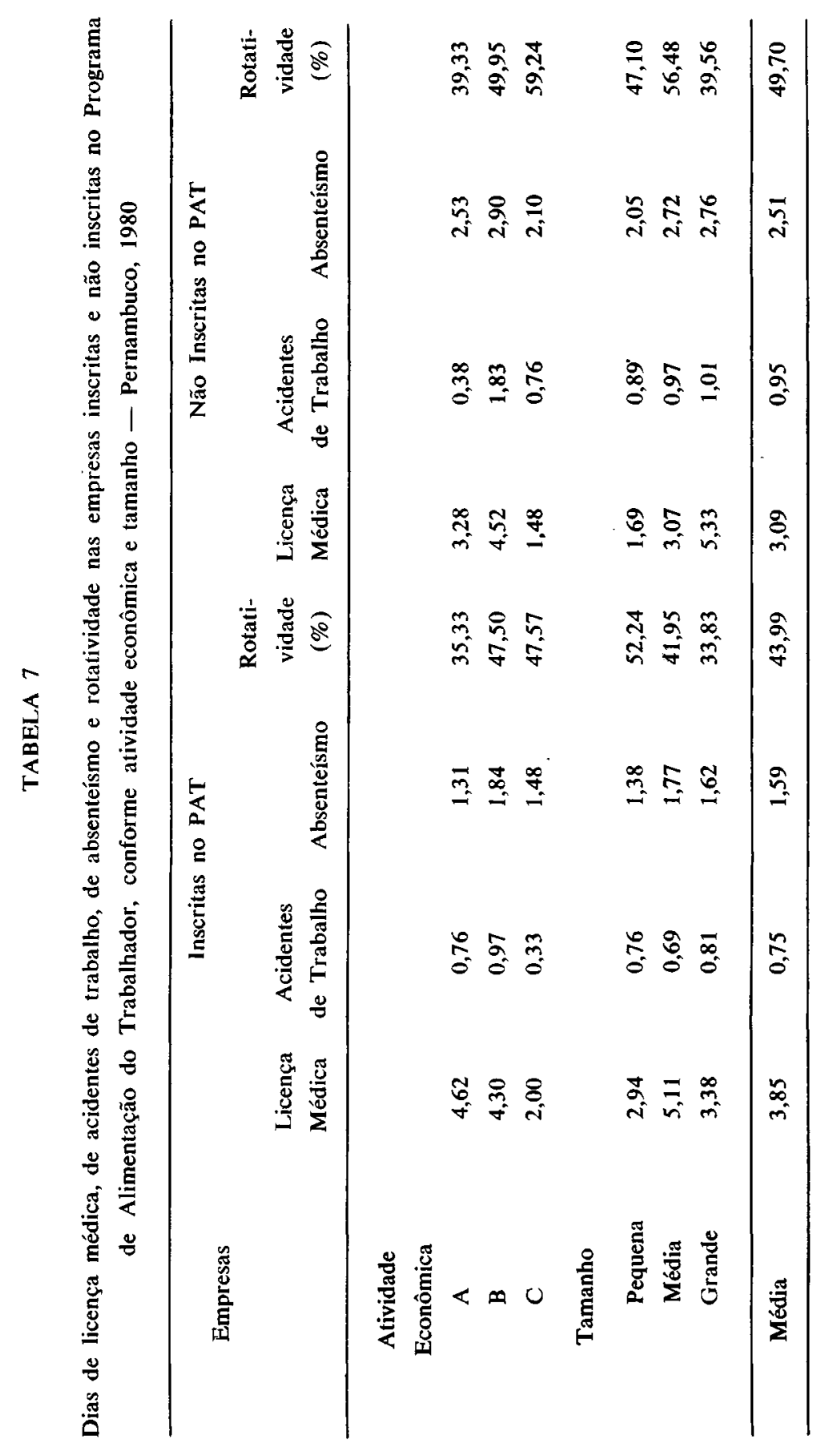


MOURA, J.B. de Avaliação do programa de alimentação do trabalhador, no Estado de Pernambuco, Brasil. Rev. Saúde públ., S. Paulo, 20: 115-28, 1986.

Licenças Médicas, Acidentes de Trabalho, Absenteísmo e Rotatividade em Empresas Inscritas e não Inscritas no PAT, em 1980

Comparando-se os dias de licença médica por trabalhador/ano nos grupos experimental e controle, verifica-se um menor número de ausências no grupo controle, exceção das empresas de grande porte e de atividade econômica $B$ (Tabela 7); contudo, os testes estatísticos aplicados não confirmam a hipótese de existir diferenças significativas entre as médias das inscritas e não inscritas no PAT.

Observando a média de dias perdidos em acidentes por trabalhador/ano, percebe-se que a mesma foi inferior ao grupo experimental, ou seja, 0,75 contra 0,95 no grupo controle; todavia, tal diferença mostrou-se insignificante aos testes estatísticos.

A média do absenteísmo no grupo experimental $(1,59)$ foi inferior à do grupo controle $(2,51)$, tendo os resultados dos testes estatísticos reforçado a hipótese da redução deste indicador entre as empresas incentivadas.

A análise da rotatividade das empresas dos grupos estudados revelou, em média, maior prevalência deste indicador entre as não inscritas no PAT. Entretanto, os testes estatísticos aplicados favo: recem a hipótese de inexistir diferença significativa entre as médias dos grupos experimental e controle.

\section{Conteúdo Energético/Protéico das Refeições}

Em todas as refeições analisadas contendo abaixo, igual ou acima de 1.400 calorias - observa-se um NDpCal\% na faixa ou acima da recomendada. Constatou-se que 48 empresas fornecem menos de 1.400 calorias e, dentre estas, 26 apresentam NDpCal\% acima de 12 (Tabela 8 ).

\section{TABELA 8}

Conteúdo energético oferecido no almoço das empresas inscritas no Programa de Alimentação do Trabalhador, segundo NDpCal\% e tipo de serviço - Pernambuco, 1982.

\begin{tabular}{|c|c|c|c|c|c|c|}
\hline \multirow{3}{*}{ Calorias } & \multirow{3}{*}{ NDpCal\% } & \multicolumn{5}{|c|}{ Tipo de Serviço } \\
\hline & & \multirow[t]{2}{*}{ Próprio } & \multicolumn{3}{|c|}{ Terceiros } & \multirow[t]{2}{*}{ Total } \\
\hline & & & Comodato & Ref. Pront. & Ref. Con. & \\
\hline \multirow{2}{*}{$<1400$} & 6 a 12 & $\begin{array}{c}12 \\
(54,55 \%)\end{array}$ & $\begin{array}{c}1 \\
(4,54 \%)\end{array}$ & $\begin{array}{c}9 \\
(40,91 \%)\end{array}$ & 0 & $\begin{array}{c}22 \\
(100,00 \%)\end{array}$ \\
\hline & $>12$ & $\begin{array}{c}14 \\
(53,85 \%)\end{array}$ & $\begin{array}{c}3 \\
(11.54 \%)\end{array}$ & $\begin{array}{c}7 \\
(26,92 \%)\end{array}$ & $\begin{array}{c}2 \\
(2.69 \%)\end{array}$ & $\begin{array}{c}26 \\
(100,00 \%)\end{array}$ \\
\hline \multirow{2}{*}{$\geqslant 1400$} & 6 a 12 & $\begin{array}{c}11 \\
(91,67 \%)\end{array}$ & 0 & $\left(\begin{array}{c}1 \\
(8,33 \%)\end{array}\right.$ & 0 & $\begin{array}{c}12 \\
(100,00 \%)\end{array}$ \\
\hline & $>12$ & $\begin{array}{c}12 \\
(75,00 \%)\end{array}$ & $(18,75 \%)$ & $\left(\frac{1}{6,25 \%)}\right.$ & 0 & $\begin{array}{c}16 \\
(100,00 \%)\end{array}$ \\
\hline \multirow{2}{*}{ Total } & & 49 & 7 & 18 & 2 & 76 \\
\hline & & $(64,47 \%)$ & $(9,21 \%)$ & $(23,69 \%)$ & $(2,63 \%)$ & $(100,00 \%)$ \\
\hline
\end{tabular}


MOURA, J.B. de Avaliação do programa de alimentação do trabalhador, no Estado de Pernambuco, Brasil. Rev. Saúde públ., S. Paulo, 20: 115-28, 1986.

Com referência às empresas que fornecem refeições com mais de $1.400 \mathrm{ca}$ lorias (28), verifica-se que 16 delas apresentam NDpCal\% superior a 12 e, conseqüentemente, cardápio de elevado custo.

Considerando-se o efetivo de empresas cujos cardápios foram analisados ( 76 empresas), verificou-se que apenas 12 $(15,78 \%)$ atendem às normas de energia/ proteína, preconizadas pela Lei $6.321 / 76$.

\section{Distribuição do Preço das Refeições Servidas aos Trabalhadores}

Antes da inscrição no PAT, das empresas que forneciam alimentação (almoço) aos seus empregados, em 1976, $22,22 \%$ cobravam valores inferiores a $0,3 \%$ do salário-mínimo da época; $66,67 \%$ entre 0,3 e $0,5 \%$ e $11,11 \%$ entre 0,5 e $0,7 \%$. Parece que a inscrição das empresas no Programa contribuiu para elevar o custo das refeições fornecidas aos trabalhadores, uma vez que hou- ve redução do número de trabalhadores cujo desconto/refeição incidia na faixa de $0,5 \%$ do salário-mínimo, e consequiente elevação na faixa de 0,5 a $0,7 \%$, sendo de notar ainda que algumas empresas determinaram preço superior a $0,7 \%$, anteriormente inexistente (Tabela 9). Contudo, é possível que este efeito seja consequiência da queda real do poder aquisitivo do salário-mínimo.

Por outro lado, se nas empresas do grupo experimental forem considerados os dias perdidos por trabalhador por motivo de licença médica $(3,85)$, acidentes de trabalho $(0,75)$ e absenteísmo $(1,59)$, chegar-se-á a um total de 6,19 dias por trabalhador/ano; enquanto que no grupo controle esses indicadores totalizam 6,55 dias, levando à hipótese de que o Programa ainda não alcançou os seus objetivos. E possível que o não cumprimento das normas referentes ao conteúdo energético-protéico das refeições esteja contribuindo para tal situação.

TABEIA 9

Distribuição percentual do preço da refeição em relação ao salário-mínimo da época, nas empresas inscritas no Programa de Alimentação do Trabalhador -

Pernambuco, $1976 / 1980$.

\begin{tabular}{lcccccc}
\hline \multirow{7}{*}{ Ano } & & \multicolumn{7}{c}{ do Salário-mínimo } & Total \\
& $0,00-\mid 0,3$ & $0,3-\mid 0,5$ & $0,5-\mid 0,7$ & $0,7-\mid 0,9$ & $>0,9$ & \\
\hline 1976 & 22,22 & 66,67 & 11,11 & 0,00 & 0,00 & 100,00 \\
1977 & 18,52 & 51,85 & 18,52 & 7,40 & 3,70 & 100,00 \\
1978 & 40,00 & 30,00 & 20,00 & 5,00 & 5,00 & 100,00 \\
1979 & 20,34 & 54,25 & 16,95 & 3,38 & 5,08 & 100,00 \\
1980 & 40,99 & $37,70$. & 18,03 & 0,00 & 3,28 & 100,00 \\
\hline
\end{tabular}

\section{CONCLUSOESS}

A análise dos resultados possibilita algumas inferências:

1. Atuação muito limitada do PAT, abrangendo apenas $2,01 \%$ das uni- dades cadastradas pela Federação das Indústrias do Estado de Pernambuco;

2. Incentivo fiscal como principal motivador da participação no Progra- 
MOURA, J.B. de Avaliação do programa de alimentação do trabalhador, no Estado de Pernambuco, Brasil. Rev. Saúde públ., S. Paulo, 20: 115-28, 1986.

ma, seguindo-se o benefício social para o empregado e a redução de atrasos e faltas;

3. Indecisão da Diretoria e desconhecimento da Lei 6.321/76 como principais razões para a não inscrição das empresas no PAT;

4. Papel irrelevante dos incentivos fiscais na criação de serviços de alimentação (menos de $1 / 3$ das empresas beneficiadas iniciaram o fornecimento de refeições concomitantemente à sua inscrição no Programa);

5. Não interferência da participação do Programa quanto ao indicador dias perdidos em acidentes/trabalhador/ ano;

6. Redução no absenteísmo nas empresas após a participação no Programa;

7. Nenhuma influência da participação no PAT quanto à rotatividade nas empresas;

8. Maior percentual de trabalhadores percebendo até dois salários-mínimos, principalmente nas empresas do grupo controle;

9. Correlação PAT/melhoria de níveis salariais;

10. Atendimento às normas energético-protéicas estabelecidas pelo Programa de apenas $15,78 \%$ das refeições analisadas;

11. Elevação do preço das refeições ao que tudo indica coincidente com a inscrição das empresas no PAT.

\section{RECOMENDAÇÕES}

Algumas ações possivelmente resultariam numa mais eficiente e eficaz atuação do PAT, entre as quais:

1. Aprofundar estudos no sentido de viabilizar estratégias que realmente motivem as empresas a se inscreverem no PAT, direcionados especialmente às de pequeno porte, pela sua expressão numérica e reduzida participação no Programa, objetivando estender os benefícios ao maior número possível de trabalhadores;

2. Realizar planejamento direcionado a uma maior divulgação dos benefícios oriundos da implantação do Programa, não somente os diretamente relacionados ao trabalhador (saúde e produtividade), como os concernentes aos interesses da empresa (alternativas a nível de incentivo fiscal);

3. Estabelecer estratégias adequadas para implantação do Programa nas empresas de comércio e prestação de serviços, paralelamente à análise do tipo de serviço de alimentação a ser adotado;

4. Desenvolver estudo epidemiológico sobre a saúde dos trabalhadores;

5. Intensificar as atividades dos Serviços Especializados de Segurança e Medicina do Trabalho da Comissão Interna de Prevenção de Acidentes (CIPA) e das Comissões de Fábrica de cada empresa, de modo a acompanhar a modernização das máquinas, métodos e equipamentos;

6. Adotar tratamento diferenciado para as empresas que utilizam serviço de alimentação próprio, tornando efetivo o financiamento para instalação de cozinhas e refeitórios, por ser aquela modalidade a que melhor atende às exigências do Programa, em relação às quotas energético-protéicas;

7. Intensificar as ações de supervisão dos serviços de alimentação, objetivando maior controle qualitativo e quantitativo das refeições servidas aos trabalhadores;

8. Fixar a contrapartida do trabalhador em função do(s) salário(s)-mínimo(s) percebido(s), ao invés do custo da refeição. 
MOURA, J.B. de Avaliação do programa de alimentação do trabalhador. no Estado de Pernambuco, Brasil. Rev. Saúde públ., S. Paulo, 20: 115-28, 1986.

MOURA. J.B. de [An evaluation of the Meals Program for Workers in Pernambuco State Brazil]. Rev. Saúde públ., S. Paulo, $20: 115-28,1986$.

ABSTRACT: The establishment, implementation and impact of the Meals Program for Worlkers (MPW) were evaluated in a total of 130 industries in the state of Pernambuco (Northeast Brazil). Of these, 85 had been enrolled in the Program from 1977 to 1980 (experimental group) and 45 had not (centrol group). The reasons for the implantation or not of the Program, as well as the health conditions, the industrial. accident. absenteeism and turn-over rates among employees, were determined, taking into consideration the economic activity and the size of the industries. In the experimental group the analysis was made from one year before the enrolment in the Program and covered industries which had enjoyed the benefits of $1,2,3$ or 4 years of fiscal incentive. The data for the control group were collected in 1980 only and were used as a parameter for the evaluation of the impact indicators of the Program. The analysis of the mienus suggests that a small number of industries were serving meals in accordance with the minimal amounts of energy and protein recommended by the Law n. ${ }^{\circ} 6.321 / 76$, that is, a minimum of $1,400 \mathrm{cal}$ and NDPcal\% higher than 6 . The increase in the price of the meal/employee was also determined for the same period of time. It has been demonstrated that government incentives were the motivation for the industries' participation in the Program and that a high percentage of these industries already cffered meals to their employees before the Program began. Ignorance of the Law and the administrative indecision were among the reasons for the non-implementation of the Program. A significant number of employees in both groups received less than two legal minimum salaries although the industries of the experimental group offered higher wages to their employees. The analysis of the impact indicators in both groups leads to the conclusion that the number of industrial accidents, health conditions and turn-over rate among employees have remained unchanged, but absenteeism had been reduced by the Program.

UNITERMS: Nutrition programs. Evaluation Studies. Workers.

\section{REFERENCIAS BIBLIOGRÄFICAS}

1. ARRUDA, B.K.G. de Três pronunciamentos. Brasília, Instituto Nacional de Alimentação e Nutrição, 1976.

2. CHAVES, N. Nutrição e trabalho físico. In: Chaves, N. Nutrição básica e aplicada. Rio de Janeiro, Guanabara Koogan, 1978, p. 197-205.

3. FAO. La nutrición y el rendimiento en el trabajo. Roma, 1962. (Campaña Mundial contra el Hambre: Estúdio Básico, 5).

4. FAO. Nutrition and working efficiency Roma, 1966.

5. INSTITUTO NACIONAL DE ALIMENTAÇÃO E NUTRIÇÃO. Relatório anual 1975. Brasília, 1975. (Documento Técnico $04 / 75$ ).

6. INSTITUTO NACIONAL DE ALIMENTAÇÃO E NUTRIÇÃO. Programa Nacional de Alimentação e Nutrição
- PRONAN 1976-1979. Brasilia. 1976. (Documento Técnico INAN-06) $76)$.

7. LEITE, E.M.; MELO, M.J. de \& SILVEIRA, P.P. da $O$ SENAI e a pequena $e$ média empresa: subsidios para uma proposta de atuação. São Paulo, Serviço Nacional de Aprendizagem Industrial, 1980. p. 11-26.

8. LEUNG, W.T.W. \& FLORES, M. Tabla de composicion de alimentos para uso en America Latina. Guatemala, Instituto de Nutrición de Centro America y Panamá. 1961

9. MENDEHALL, W. \& SCHEAFFER, R.L. Mathematical statistics with applications. Belmont. Dusching Press, 1973. p. 325-73.

10. MINISTÉRIO DO TRABALHO. Incentivos fiscais para a alimentação do trabalhador. Brasília, 1979. 
MOURA, J.B. de Avaliação do programa de alimentação do trabalhador, no Estado de Pernambuco, Brasil. Rev. Saúde públ., S. Paulo, 20: 115-28, 1986.

11. MONTEIRO, C.A. A desnutrição e o planejamento econômico social. Saúde Deb., S. Paulo (3): 58-67, abr./jun. 1977.

12. VITERI, F.E. \& TORUN, B. Ingestion calorica y trabajo fisico de obreros agricolas en Guatemala. Bol. Ofic. sanit. panamer., 78: 58-74, 1975.
13. WOLFF, F. E se a gente desse de comer ao trabalhador? Pasquim, Rio de iJaneiro, 7.13 abr. 1983. p. 7.

Recebido para publicação em 26/06/1985

Reapresentado em 02/12/1985.

Aprovado para publicação em 10/12/1985. 